\title{
Determination of Trace Mercury in Water by On-line Solid Phase Extraction and Ultraviolet Vapor Generation - ICP-MS
}

\author{
Hong-Kang Zhang ${ }^{\mathrm{a}}$, Dan-Dan Shao ${ }^{\mathrm{a}, \mathrm{b}}$, Ling-Na Zheng ${ }^{\mathrm{b}, \mathrm{c}}$, Zhong-Yuan Wang $^{\mathrm{d}}$, Bing Wang ${ }^{\mathrm{b}}$, \\ Wei-Yue Feng ${ }^{\mathrm{b}}$, and Meng Wang ${ }^{\mathrm{b}, *}$ \\ ${ }^{a}$ College of Light Industry and Food, Zhongkai University of Agriculture and Engineering, \\ Guangzhou 510225, P.R. China \\ ${ }^{b}$ CAS Key Laboratory for Biomedical Effects of Nanomaterials and Nanosafety, Institute of \\ High Energy Physics, Chinese Academy of Sciences, Beijing 100049, P.R. China \\ c University of Chinese Academy of Sciences, Beijing 100049, P.R. China \\ d South China Sea Environment Monitoring Center, State Oceanic Administration, \\ Guangzhou 510300, P.R. China
}

\section{INTRODUCTION}

Mercury $(\mathrm{Hg})$ is one of the most hazardous elements in the environment (1) and occurs from natural sources (e.g., volcanic eruption) as well as from artificial sources (e.g., coal burning, industry, etc.). Longrange atmospheric transport of mercury has led to increased levels of mercury in the environment (2) which can persist for many years. By the action of microbes, inorganic mercury can be transformed to methyl mercury, which subsequently bio-accumulates in humans, plants, and animals through the food chain (3). The toxic effects and bioavailability of mercury are dependent on the chemical species (4). For example, methyl mercury can be efficiently adsorbed by organisms, pass the blood-brain barrier, and result in high toxicity levels (4). Monitoring of mercury levels in water is crucial for environmental protection and management (5), particularly in significantly polluted areas. However, mercury concentration in water is usually extremely low. For example, it was reported that the mercury level in lake water ranges from $0.14 \sim 15 \mathrm{ng} \mathrm{L}^{-1}$, while in the ocean the average is $<10 \mathrm{ng} \mathrm{L}^{-1}$ (6). Almost all mercury in natural water is inorganic mercury $\left(\mathrm{Hg}^{2+}\right)$ (6). The ultratrace concentration of mercury in real water samples

\section{ABSTRACT}

As one of the most hazardous elements in the environment, mercury poses a threat to humans, plants, and animals. Determination of mercury in water is crucial for environmental management and toxicological research. In this study, a new method was developed for the determination of ultratrace mercury in tap and lake water based on on-line solid phase extraction (SPE) and ultraviolet vapor generation (UVG), coupled with inductively coupled plasma mass spectrometry (ICP-MS). A SPE column (C18 reverse-phase column) was used to enrich the samples and to eliminate potential interferences from matrix and reagent impurities. Formic acid of $10 \%(\mathrm{v} / \mathrm{v})$ was used to reduce the mercury ions in water into mercury vapor. Good linearity $\left(\mathrm{R}^{2}=0.995\right)$ was obtained ranging from 1-1000 $\mathrm{ng} \mathrm{L}^{-1} \mathrm{Hg}^{2+}$, with a limit of detection of $0.5 \mathrm{ng} \mathrm{L}^{-1}$ and an RSD of less than 5\%.

The developed method was validated by spike and recovery experiments and analysis of a certified reference material GBW 10050 Prawn. The results show that the SPE-UVG-ICP-MS method is sensitive, fast, precise, and cost-effective for mercury analysis, especially for natural water samples. poses challenges for analytical science and it is, therefore, crucial to develop a sensitive, accurate, and convenient analytical method.

Up to the present, various analytical techniques have successfully been developed for the determination of mercury in water (7), such as inductively coupled plasma mass spectroscopy (ICP-MS) (8), atomic fluorescence spectroscopy (AFS) (9), atomic absorption spectroscopy (AAS) (10), and inductively coupled plasma optical emission spectroscopy (ICP-OES) (11). In combination with separation techniques, such as gas chromatography, high performance liquid chromatography, and capillary electrophoresis, speciation analysis of mercury could be achieved (4). Solution nebulization is the most common means of sample introduction for the above detection techniques. However, many limitations of these methods need to be addressed when analyzing mercury in water samples, such as insufficient detection limits, severe memory effects, and low sample introduction efficiency.

As an efficient sample introduction means, vapor generation (VG) offers a unique solution to the above limitations and succeeds in the analysis of problematic water samples with high dissolved salts or complex matrixes $(12,13)$. In the VG technique, the nonvolatile analyte is transformed to volatile compounds. The generated compounds 
are separated from the matrixes by a gas-liquid separator and then introduced to an element-specific detector. The VG technique greatly improves the detection limits, eliminates the memory effect of mercury, and efficiently avoids matrix interferences (12). Mercury vapor is usually generated by chemical reductants (e.g., sodium tetrahydroborate), termed as chemical vapor generation (CVG). The VG system has been sucessfully used as the interface of HPLC and ICP-MS, greatly improving the dection limits for both methyl and inorganic mercury (14).

However, CVG usually suffers from poor reproducibility and potential interferences and contamination, mainly due to the unstable reductants and impurity of the reagents (13). Recently, ultraviolet vapor generation (UVG) has been developed as a superior method due to its unique advantages of eliminating the need of unstable reagents, decreasing the potential interferences from reagents, and conferring green chemistry to a degree (15-18). Mercury ions in water can be transformed to mercury vapor by UV irradiation in the presence of organic acid (e.g., formic acid). Besides mercury, a wide range of elements, such as $\mathrm{Br}$ (19), Se (20), and Fe (21), can also be successfully derivatized to volatile species by UVG. In this manuscript, an online solid phase extraction (SPE) column was used to trap and concentrate mercury in water and, after UVG, the mercury vapor was analyzed by ICP-MS. The developed method eliminates potential interferences from the sample matrix and reagent impurities, and achieves better sensitivity for mercury analysis.

\section{EXPERIMENTAL}

\section{Instrumentation}

The UVG system consists of a gas liquid separator, photochemical reactor, UV lamp (19W low pressure mercury lamp, Beijing Titan Instrument Co., Beijing, P.R. China), peristaltic pump (Longer Precision Pump Co., Baoding, P.R. China), C18 solid phase extraction column (sorbent: $500 \mathrm{mg} /$ volume: $3 \mathrm{~mL}$, Agela Technologies, Tianjin, P.R. China), sampling valve, and selection valve (Valco Instruments Co., USA), as shown in Figure 1. Tygon ${ }^{\circledR}$ tubing was used to connect the components and deliver the liquid. A NexION ${ }^{\circledR}$ 300D quadrupole ICP-MS (PerkinElmer, Inc., Shelton, CT, USA) was used for mercury determination. For best performance before analysis, the ICP-MS was tuned with $1 \mu \mathrm{g} \mathrm{L}^{-1}$ tuning solution. and the mass spectrometric data were collected in Time Resolving Analysis (TRA) mode. The typical parameters of the ICPMS and UVG systems are listed in Table I.

\section{Reagents}

Acetonitrile (HPLC grade), ammonium acetate (HPLC grade), formic acid (HPLC grade), nitric acid (MOS grade), hydrogen peroxide (MOS grade), sulfuric acid (G.R.), and potassium bichromate
(A.R.) were purchased from Sinopharm Chemical Reagent Beijing Co. (Beijing, P.R. China). Sodium diethyldithiocarbamate (DDTC) and mercaptoethanol were supplied by Shanghai Macklin Biochemical Co., Ltd. Ultrapure water from a Milli-Q ${ }^{\circledR}$ system $(18.2 \mathrm{M} \Omega \cdot \mathrm{cm}$,

TABLE I

Typical Parameters of the UVG-ICP-MS System

\begin{tabular}{|c|c|}
\hline Parameters & Value \\
\hline \multicolumn{2}{|c|}{$U V$ Vapor Generation } \\
\hline Carrier gas (Ar1) & $300 \mathrm{~mL} \mathrm{~min}^{-1}$ \\
\hline $\begin{array}{l}\text { Nebulizer gas } \\
\text { (Ar2) }\end{array}$ & $800 \mathrm{~mL} \mathrm{~min}^{-1}$ \\
\hline Eluting solution & $3 \mathrm{~mL} \mathrm{~min}^{-1}$ \\
\hline $\begin{array}{l}\text { Formic acid } \\
\text { solution }(10 \%)\end{array}$ & $3 \mathrm{~mL} \min ^{-1}$ \\
\hline Sample loop & $10 \mathrm{~mL}$ \\
\hline
\end{tabular}

ICP-MS

Forward power

$1400 \mathrm{~W}$

Cool gas

15.0 $\mathrm{L} \mathrm{min}^{-1}$

Auxiliary gas

$0.75 \mathrm{~L} \mathrm{~min}^{-1}$

Nebulizer

Glass concentric

Isotope determined $\quad{ }^{202} \mathrm{Hg}$

Dwell time

$100 \mathrm{~ms}$

Total time

$160 \mathrm{~s}$

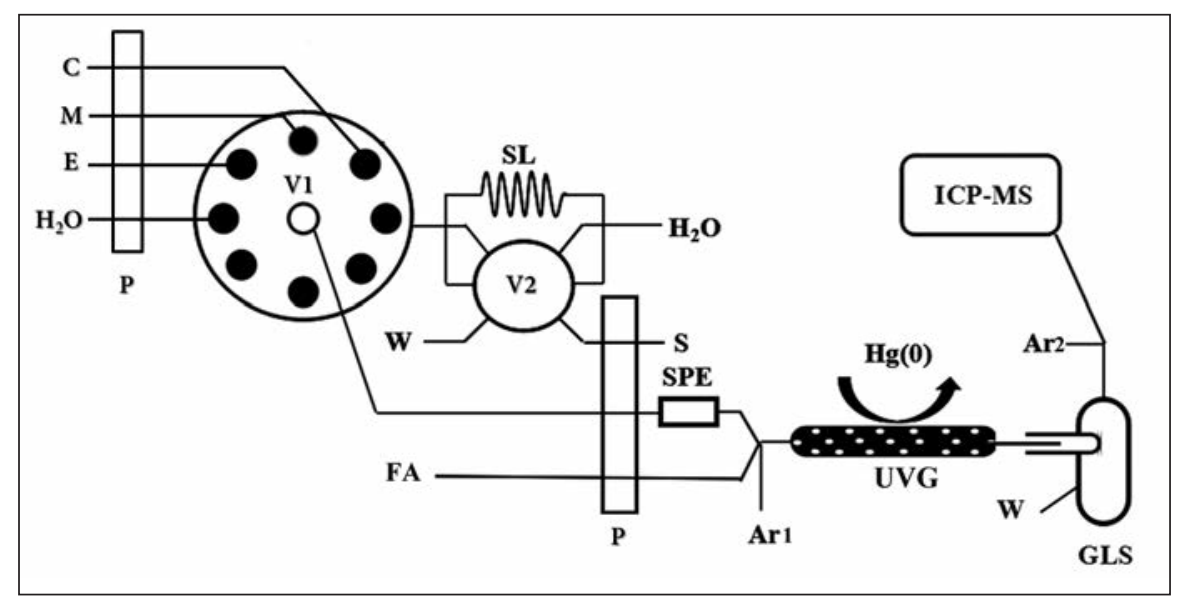

Fig. 1. Schematic diagram of the UV photochemical vapor generation system. C: column washing solution; M: modification solution; E: eluting solution; $P$ : peristaltic pump; V1: selection valve; SL: sample loop; V2: sampling valve; W: waste; FA: formic acid; S: sample; SPE: solid phase extraction column; Ar1: carrier argon gas; Ar2: nebulizer argon gas; UVG: the UV lamp and photochemical reactor; GLS: gas liquid separator. 
Millipore Corporartion, USA) was used for preparing all solutions. The mercury standard solution (1000 $\left.\mathrm{mg} \mathrm{L}^{-1}\right)$ and certified reference material GBW10050 Prawn were bought from the National Research Center for Certified Reference Materials (Beijing, P.R. China). The modification solution contained $1 \mathrm{~g} \mathrm{~L}^{-1}$ sodium diethyldithiocarbamate (DDTC); the column washing solution was $50 \%(\mathrm{v} / \mathrm{v})$ acetonitrile solution; the eluting solution contained $60 \mathrm{mmol} \mathrm{L}^{-1}$ ammonium acetate, $0.1 \%$ mercaptoethanol, and $5 \%(\mathrm{v} / \mathrm{v})$ acetonitrile.

\section{UVG Procedure}

The UVG procedure was slightly modified according to the literature $(16,17)$. Briefly, a reverse phase C18 SPE column was washed and conditioned using the DDTC modification solution. The sample solution was introduced by peristaltic pump onto the column where the mercury ions in the solution were trapped. After mercury trapping, the column was washed with a column washing solution. The trapped mercury ions were eluted with the eluting solution, mixed with the formic acid solution (10\% v/v), and introduced into the photochemical reactor where the mixture was irradiated with the UV light to generate mercury vapor. The vapor was passed through a gas liquid separator in the presence of argon carrier gas and determined by ICP-MS.

\section{Sample Preparation}

Tap water or lake water was collected after acidification with nitric acid ( $\mathrm{pH} \sim 2$ ), stored in mercury-free containers, and analyzed within one week of collection. The certified reference material GBW 10050 Prawn was accurately weighed into a centrifuge tube and digested by nitric acid and hydrogen peroxide in a closed vessel. After proper dilution, the digestion solution was analyzed by UVG-ICP-MS.

\section{RESULTS AND DISCUSSION}

\section{SPE for Mercury Enrichment and Elimination of Inter- ferences}

Mercury is usually found at a very low concentration $\left(<0.1 \mu \mathrm{g} \mathrm{L}^{-1}\right)$ in real water samples (6). The interferences from the matrixces, especially oxidants, could adversely affect mercury vapor generation. In this study, a reversed-phase C18 SPE column was used to enrich mercury and eliminate potential interferences. After trapping, the mercury ions were eluted with a thiol-containing reagent. The recovery experiments showed that the mercury ions on the column were quantitatively eluted with $8 \mathrm{~mL}$ of eluting solution containing $0.1 \%$ mercaptoethanol at a $3-\mathrm{mL} \mathrm{min}^{-1}$ flow rate, and in agreement with the literature data (17). Figure 2 shows that a higher concentration of mercapoethanol could decrease ICP-MS sensitivity, partly because of the introduction of interference from impurities. In a subsequent experiment, an eluting solution containging $0.1 \%$ mercaptoethanol was chosen. In comparison with the acidic eluting solution as reported in the literature (e.g., 0.5 $\mathrm{v} / \mathrm{v} \mathrm{HCl}$ (22), the neutral eluting buffer $(\mathrm{pH} \sim 7)$ was more compatible with the silica-based C18 column, which is normally stable at the $\mathrm{pH}$ range of $2 \sim 8$.

\section{Atomic Apectroscopy $\bigcirc$ Vol. 40(2), March/April 2019}

On the other hand, several ions and oxidants, such as the transition metals $\mathrm{Cl}^{-}, \mathrm{NO}_{3}{ }^{-}, \mathrm{NO}_{2}{ }^{-}$, etc., are recognized quenchers of the photochemical reaction (13). Here, the SPE column can remove the ions and oxidants from the samples, eliminate the potential interferences, and facilitate mercury UVG. Under similar conditions, it was reported that the transition metals at the concentrations of $10 \mathrm{mg} \mathrm{L}^{-1}$ would not cause detectable interference during UVG (17). The results obtained from the standard solution and the recovery experiments show that no interferences were found in the present study.

\section{UVG Reagent and Mechanism}

In this manuscript, the irradiation time (i.e., sample flow rate through the UVG reactor) was about 15 seconds when using a sample delivery flow rate of $3 \mathrm{~mL}$ $\min ^{-1}$. Using an intermittent stopflow sequence for sample introduction as described in the literature (19), we compared the irradiation time from 10-40 seconds and found no obvious change in the mercury signal over the irradiation time. The carrier gas (Ar1) flow rate of $300 \mathrm{~mL} \mathrm{~min}^{-1}$ through the gas liquid separator was chosen after careful consideration of the efficiency of gas-liquid separation and transport of mercury gas. To

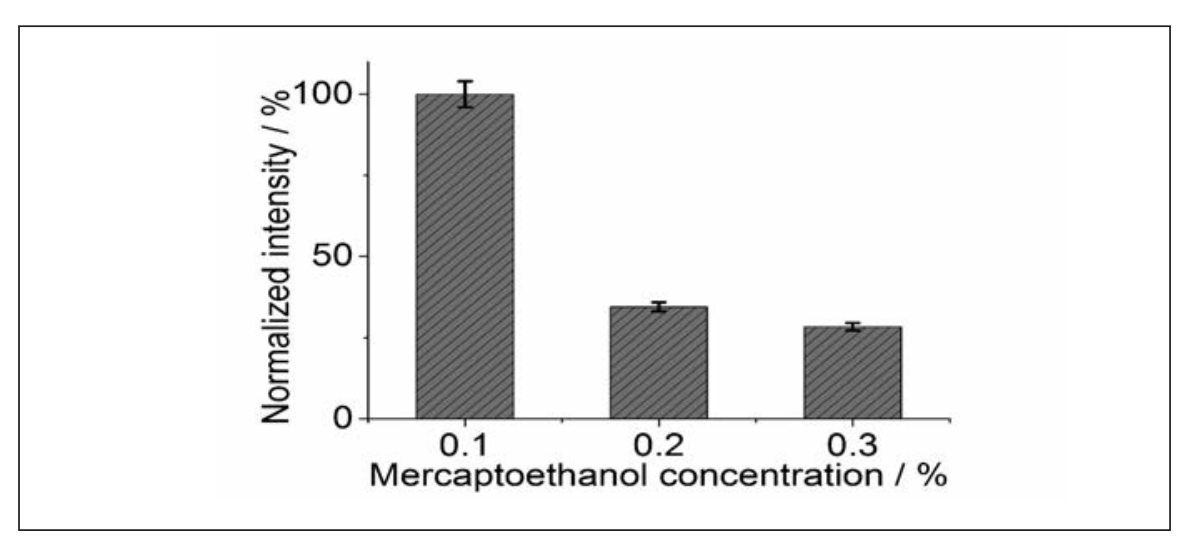

Fig. 2. Effects of mercaptoethanol concentration (\%, $v / v)$ on mercury intensity determined by UVG-ICP-MS. 
obtain the best response, the flow rate of the nebulizer gas (Ar2) was optimized to $800 \mathrm{~mL} \mathrm{~min}^{-1}$.

The UVG efficiency is dependent on the UVG reagent used. According to the literature, many chemicals, such as aldehydes, alcohols, and carboxylic acids, are reported capable of inducing UVG of mercury (13). Among them, formic acid serves as the preferred UVG chemical due to its broad efficacy and high efficiency for the UVG process $(13,23)$. It was reported that in the UVG process formic acid has the highest efficiency in comparison to other low-weight organic acids (24). The effects of the formic acid concentration on mercury intensity in ICP-MS are shown in Figure 3. When adding formic acid as the UVG reagent, stable and significant signals of mercury were achieved in ICP-MS. A plateau of mercury intensity was reached when the mercury standard solution was mixed with $10 \%$ (v/v) formic acid and was then irradiated with UV light. Therefore, $10 \%(\mathrm{v} / \mathrm{v})$ formic acid was chosen as the UVG reagent.

Under UV irradiation, formic acid can yield a complex mixture of radicals, which are able to reduce inorganic mercury to elemental mercury vapor, as shown in the following reaction (16):

$$
\mathrm{Hg}^{2+}+\mathrm{HCOOH} \rightarrow \mathrm{Hg}^{0}+\mathrm{CO}_{2}+\mathrm{H}_{2}
$$

In addition, methylmercury can also be reduced to mercury vapor by a similar photochemical process at these conditions (13). Therefore, total mercury in water samples can be accurately determined by UVG ICP-MS.

\section{Determination of Mercury Ions in Water Samples}

After ICP-MS tuning, the analytical figures of merit of the developed method were evaluated using a series of standard mercury solutions. The typical spectra of UVG-ICP-MS are shown in Figure 4. The linear range of the mercury determination was 1-1000 $\mathrm{ng} \mathrm{L}^{-1}$ and the calibration curve had a better than 0.995 linear correlation coefficient. The limit of detection and limit of quantification were 0.5 and $1.6 \mathrm{ng} \mathrm{L}^{-1}$, which were calculated based on 3 times and 10 times the standard deviation of 11 measurements of a blank solution, respectively.

Using the developed method, the mercury concentrations in tap water and lake water were determined by UVG-ICP-MS. The tap water sample was also spiked with $0.100 \mu \mathrm{g} \mathrm{L}^{-1}$ mercury ion for the recovery experiment. The developed method was further validated by analysis of the diluted digestion solution of certified reference material GBW 10050 Prawn. The results in Table II show that the spike recovery was $98 \%$ and the determined data of the certified reference material were in agreement with the certified value.

It should be noted that biological samples, such as the prawn CRM, usually contain a relatively high concentration of mercury and thus UVG is not always necessary for mercury analysis by ICP-MS. The developed method can be also applied for the analysis of these biological samples after acid digestion and a high dilution of the samples.

\section{CONCLUSION}

A new method for the determination of ultratrace mercury in water was developed based on on-line solid phase extraction and UVG-ICP-MS detection. A solid phase extraction column was used to enrich mercury in the samples and eliminate potential interferences from the sample matrix and reagent impurities. Formic acid

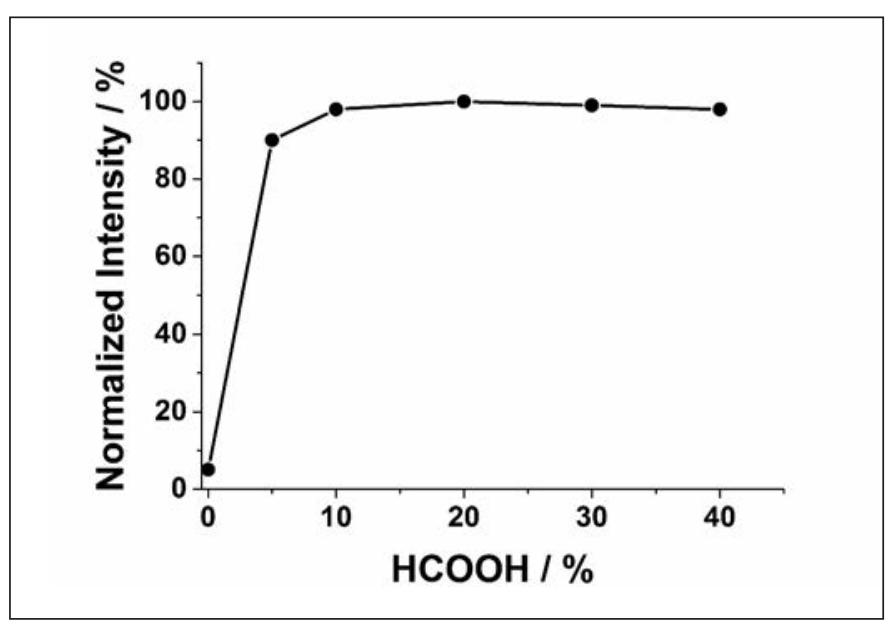

Fig. 3. Effects of formic acid concentration on the normalized intensity of mercury determined by UVG-ICP-MS. The solution flow rate was $3 \mathrm{~mL} \mathrm{~min} \mathrm{~m}^{-1}$.

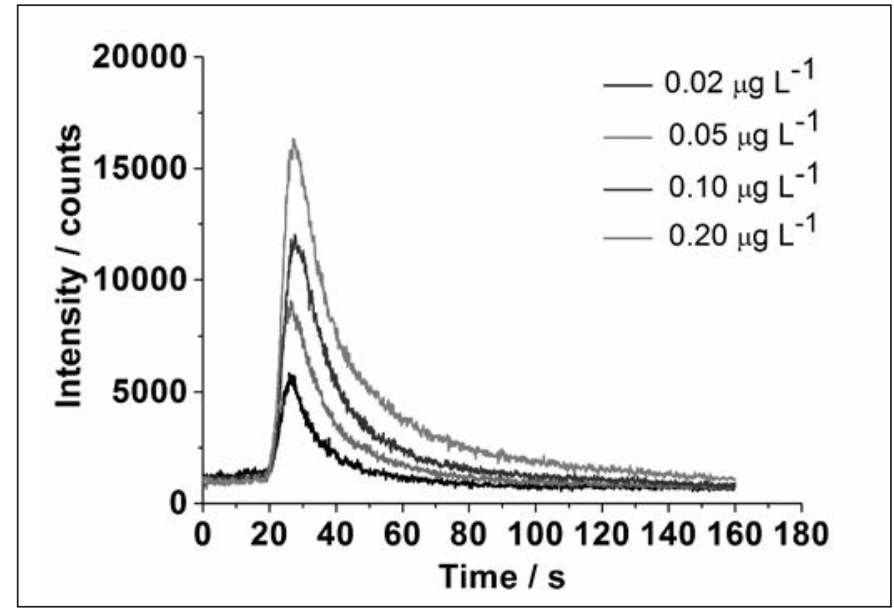

Fig. 4. Typical spectra of $\mathrm{Hg}^{2+}$ standard solutions $(0.02,0.05$, 0.1 , and $0.2 \mu g L^{-1}$ ) determined by UVG-ICP-MS. 


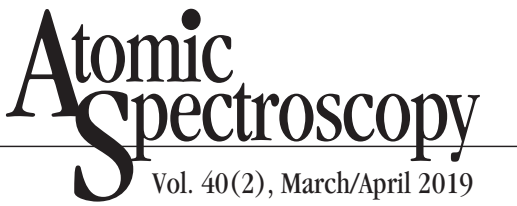

was mixed with the samples, reducing the mercury ions into mercury vapor. In comparison with traditional vapor generation methods using chemical reductants, the UVG method eliminates the need for fresh and unstable reductants, achieves high efficiency for vapor generation, and thus enhances the limit of detection. UVG-ICP-MS is a sensitive, fast, precise, and costeffective method for mercury analysis, especially for ultratrace mercury in natural water.

\section{ACKNOWLEDGMENTS}

This work was supported by the National Natural Science Foundation of China (Grant No. U1432241, 41406093, and 11575209) and the National Basic Research Program of China (Grant NO. 2016YFA0201604).

\section{CONFLICT OF INTEREST}

The authors have no conflict of interest to declare.

Received January 8, 2019.

\section{REFERENCES}

1. C.T. Driscoll, R.P. Mason, H.M. Chan, D.J. Jacob, and N. Pirrone, Environ. Sci. Technol. 47, 4967 (2013).

2. E.D. Stein, Y. Cohen, and A.M. Winer, Environ. Sci. Technol. 26, 1 (1996).

3. A.T. Schartup, R.P. Mason, P.H. Balcom, T.A. Hollweg, and C.Y. Chen, Environ. Sci. Technol. 47, 695 (2013).

4. M. Leermakers, W. Baeyens, P. Quevauviller, and M. Horvat, TrAC - Trends Anal. Chem. 24, 383 (2005).

5. S.M. Ullrich, T.W. Tanton, and S.A. Abdrashitova, Crit. Rev. Environ. Sci. Technol. 31, 241 (2001).

TABLE II

Results of Mercury Determination by UVG-ICP-MS ( $\left.\mu g \mathrm{~L}^{-1}\right)$

\begin{tabular}{lccc}
\hline Samples & $\begin{array}{c}\mathrm{Hg} \\
\text { Detected }\end{array}$ & $\begin{array}{c}\mathrm{Hg} \\
\text { Recovery }\end{array}$ & $\begin{array}{c}\mathrm{Hg} \\
\text { Certified }\end{array}$ \\
\hline Tap water & $0.035 \pm 0.002$ & - & - \\
Tap water spiked with $0.1 \mu \mathrm{g} \mathrm{L}^{-1}$ & $0.133 \pm 0.004$ & $98 \%$ & - \\
Lake water 1 & $0.028 \pm 0.002$ & - & - \\
Lake water 2 & $0.043 \pm 0.002$ & - & - \\
Lake water 3 & $0.079 \pm 0.003$ & - & - \\
GBW 10050 Prawn & $47 \pm 7$ & - & $49 \pm 8$ \\
\hline
\end{tabular}

Results are shown in Average \pm SD $(n=3)$.

6. A. Mousavi, R.D. Chávez, A.M.S. Ali, and S.E. Cabaniss, Environ. Forensics 12, 14 (2011).

7. K. Leopold, M. Foulkes, and P. Worsfold, Anal. Chim. Acta 663, 127 (2010).

8. M. Wang, W. Feng, J. Shi, F. Zhang, B. Wang, M. Zhu, B. Li, Y. Zhao, Z. Chai, Talanta 71, 2034 (2007).

9. X. Xu, R. Liu, C. Wei, W. Qiu, and Y. Gao, At. Spectrosc. 34, 238 (2013) .

10. J.C.A. De Wuilloud, R.G. Wuilloud, J.A. Gásquez, R.A. Olsina, and L.D. Martinez, At. Spectrosc. 22, 398 (2001).

11. Z. Benzo, M. Quintal, E. Marcano, J. Salas, C. Gómez, A. Garaboto, and M. Murillo, At. Spectrosc. 21, 165 (2000).

12. Y. Gao, R. Liu, and L. Yang, Chinese Sci. Bull. 58, 1980 (2013).

13. R.E. Sturgeon, J. Anal. At. Spectrom. 32, 2319 (2017).

14. K.J. Chen, I.H. Hsu, and Y.C. Sun, J. Chromatogr. A. 1216: 8933 (2009).

15. X.M. Guo, R.E. Sturgeon, Z Mester, and G.J. Gardner, Anal. Chem. 76: 2401(2004).

16. C.B. Zheng, Y. Li, Y. He, Q. Ma, and X. Hou, J. Anal. At.
Spectrom. 20, 746 (2005).

17. D. Qin, F. Gao, Z. Zhang, L. Zhao, J. Liu, J. Ye, J. Li, and F. Zheng, Spectrochim. Acta Part B At. Spectrosc. 88, 10 (2013) .

18. G. Chen, B. Lai, N. Mei, J. Liu, and X. Mao, Spectrochim. Acta Part B, At. Spectrosc. 137, 1 (2017).

19. R. Sturgeon, Anal. Chem. 87, 3072 (2015).

20. X.M. Guo, R.E. Sturgeon, Z Mester, and G.J. Gardner, Anal. Chem. 75, 2092 (2003).

21. C.B. Zheng, R.E. Sturgeon, C.S. Brophy, S.P He, and X.D. Hou, Anal. Chem. 82, 2996 (2010).

22. R.M. Blanco, M.T. Villanueva, J.E.S. Uría, and A. Sanz-Medel, Anal. Chim. Acta 419, 137 (2000).

23. H. Duan, N. Zhang, Z. Gong, W. Li, and W. Hang, Spectrochim. Acta Part B, At. Spectrosc. 120, 63 (2016).

24. Y.G. Yin, J.F. Liu, B. He, E.L. Gao, and G.B. Jiang, J. Anal. At. Spectrom. 22, 822 (2007). 